\title{
Patient adherence issues in the treatment of hepatitis C
}

\author{
This article was published in the following Dove Press journal: \\ Patient Preference and Adherence \\ 23 May 2014 \\ Number of times this article has been viewed
}

\begin{abstract}
The current standard-of-care treatments for chronic hepatitis $\mathrm{C}$, based on a bitherapy that combines peginterferon alpha- $2 \mathrm{a}$ or $-2 \mathrm{~b}$ and ribavirin for all genotypes, and on a triple therapy with the addition of an antiprotease specifically for genotype 1, are associated with a limited adherence that decreases their efficacy. The main factors limiting adherence are difficulties in taking the treatment and side effects that worsen the quality of life of the patients. Programs of therapeutic education are essential to improve adherence, quality of life, likelihood of viral suppression, improvement of liver disease, and decrease of late complications. Therapeutic education should be understood as an acquisition of decisional, technical, and social competency with the purpose of making the patient able to make health choices, realize their own life plans, and use health care resources in the best manner. The patient should be placed in the center of an organization, comprising various care workers who include social service professionals and medical staff. For hepatitis $\mathrm{C}$, therapeutic education may be separated into three phases: a first phase corresponding to the educative diagnosis; a second phase corresponding to support during treatment; and the third phase corresponding to support after treatment. Therapeutic education is performed using various instruments and methods specifically adapted to the needs and expectations of individual patients. Upcoming treatments for hepatitis $\mathrm{C}$, with evidence for high efficacy, few side effects, and shorter duration, will certainly change the landscape of adherence and the management of therapeutic education.
\end{abstract}

Keywords: adherence to treatment, quality of life, therapeutic education, hepatitis C

\section{Introduction}

Infection with the hepatitis $\mathrm{C}$ virus (HCV) represents one of the commonest chronic infectious diseases, estimated to affect 170 million patients worldwide. It is a leading cause of chronic liver disease and is associated with a high risk of developing cirrhosis and hepatocellular carcinoma. ${ }^{1-3} \mathrm{HCV}$ infection is related to various genotypes, with genotype 1 being the commonest in many parts of the world. ${ }^{1-3}$

For the past decade, the current standard-of-care treatment for chronic hepatitis $\mathrm{C}$ has been based on a bitherapy that combines peginterferon (PEG-IFN)-2a or -2b and ribavirin (RBV) for 24-48 weeks. This treatment is associated with a sustained virological response in over $50 \%$ of all patients, with variation according to the different genotypes. ${ }^{1-3}$ In patients with genotype 1 treated for 48 weeks, a sustained virological response was achieved in only $40 \%-45 \%{ }^{1-3}$

Since 2011, a triple therapy combining PEG-IFN/RBV and telaprevir (TVR) or boceprevir (BOC), which are NS3/4A protease inhibitors (PIs), has become the new standard of care for treatment of genotype $1 \mathrm{HCV}$ infection and is associated with a
Correspondence: Dominique Larrey Département d'Hépato-

Gastroentérologie et Transplantation, Hôpital Saint Eloi, 80 rue Augustin Fliche, 34295 Montpellier Cedex 5, France

Tel +33467337061

Fax +33467330257

Email dom-larrey@chu-montpellier.fr 
$30 \%$ increase in sustained virological response..$^{4-7}$ Despite this marked improvement, there are still many treatment failures and unmet needs. ${ }^{8}$ The major cause of therapeutic failures with bitherapy and triple therapy is ascribed to poor adherence..$^{8-11}$ First, it is important to define what is meant by adherence. Usually, adherence refers to how closely the patient follows the treatment regimen as recommended by the care provider with respect to timing, dosage, and frequency. ${ }^{12}$ There are several nonadherence definitions that correspond to missed doses, involving either the care provider or the patients themselves. ${ }^{12}$ Herein, we will consider only patient-driven adherence and exclude nonadherence issues related to the absence of response to antiviral treatment, which results from the characteristics of the virus and the host immune system. ${ }^{12-14}$

The purpose of this review is to analyze and discuss the factors that modulate patient-driven adherence to treatment of HCV infection, the impact on health-related quality of life (HRQOL), and a means of improvement for treatment - in particular, through therapeutic education (TE).

\section{Patient-driven adherence to treatment of HCV infection}

The adherence of the patient during HCV infection and its treatment is modulated by various parameters. ${ }^{9-20}$

\section{Conditions for receiving the treatment}

The conditions for receiving the treatment may be unfavorable for the following reasons:

1. Poor baseline knowledge of the disease and its transmission: route of contamination, natural history of HCV infection, symptoms, and risks of complications - in particular, cirrhosis and hepatocellular carcinoma. ${ }^{15}$

2. Poor knowledge of factors that aggravate $\mathrm{HCV}$ infection: comorbidities including drug addiction, alcohol abuse, obesity, metabolic syndrome, diabetes, and

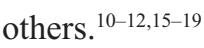

3. Poor social conditions: lack of familial support; difficulties with, for example, environment, occupation, social security, and insurance. ${ }^{12-18}$

4. Poor knowledge of the antiviral treatment: purpose of the treatment; potential health benefits; drugs used for antiviral effects (PEG-IFN/RBV and, for genotype 1, antiproteases); route of administration; duration of treatments; side effects; risk of drug interactions with co-medications; judgment of efficacy; tolerance; and other factors. ${ }^{12-15,20}$

5. Difficulties in taking the treatment. This point is particularly illustrated by triple therapy, which requires numerous pills at inconvenient times with fatty meals, in addition to other drugs used to control side effects and other potential diseases, as well as subcutaneous injection of interferon. ${ }^{4-8}$

\section{Tolerance of the treatment}

Treatment of HCV infection tolerance is variable from one patient to another and in ways that are not always predictable. Nevertheless, the side effects of the treatment are generally constant and sometimes very severe. ${ }^{1-3,8-11}$ These side effects represent the main reason for dose reduction and premature discontinuation of therapy. ${ }^{1-3,8-11}$

Indeed, in the pivotal clinical trials for bitherapy, PEGIFN alpha- $2 \mathrm{a}$ or $-2 \mathrm{~b} / \mathrm{RBV}$, adverse effects from the drugs were the primary cause for $10 \%-14 \%$ of the premature discontinuations of the treatment and for $32 \%-42 \%$ of the dose modifications. ${ }^{1-3,9}$ The duration and/or dosage of therapy (PEG-IFN alpha/RBV) were inferior to $80 \%$ of assigned treatment regimens in $21.6 \% .{ }^{10}$ Prospective studies performed thereafter in a real-life setting (with patients not selected according to the very restrictive criteria of clinical trials) have shown that adequate adherence was decreased to $60 \%$ because of adverse side effects. ${ }^{11,21}$

The main side effects that affect adherence have already been extensively reviewed. ${ }^{8-11}$ Briefly, the main side effects of PEG-IFN are marked asthenia, flu-like syndrome, neutropenia, infections, thrombopenia, sleep alteration, and, especially, depression or other psychiatric disorders (in $15 \%-60 \%)^{8-11,21-25}$ The main side effects of RBV are marked anemia, skin reactions, digestive disorders, and weight loss. ${ }^{8-11,22}$ The safety profile of triple therapy with PIs reflects the known profile of PEG-INF/RBV. The addition of PIs is responsible for incremental anemia and dysgeusia with BOC and incremental anemia, frequent skin reactions, renal failure, and gastrointestinal disorders with TVR..$^{47}$ Discontinuation of treatment owing to adverse events ranged from $8 \%-16 \%$ with BOC-based triple therapy and from $10 \%-15 \%$ with TVRbased triple therapy in Phase III trials. ${ }^{4-7}$ Side effects of triple therapy have been specifically evaluated in cirrhotic patients with a previous viral response failure to bitherapy in a real-life setting in the French Agence Nationale de la Recherche sur le Sida et les Hépatites (ANRS) CO20 Compassionate Use of Protease Inhibitors in viral C Cirrhosis (CUPIC) study. ${ }^{26}$ During the first 16 weeks of treatment with BOC or TVR, death occurred in $1.3 \%-2.0 \%$ of the cases, serious adverse events in $38.4 \%-48.6 \%$ of the cases, discontinuation for serious adverse events in $7.4 \%-14.5 \%$ of the cases, hepatic decompensation in $4.4 \%$ of the cases, marked anemia in $29.7 \%-32.7 \%$ of the cases, infection grade $3 / 4$ in $2.5 \%-8 \%$ of the cases, and rashes 
of grade 3 in $6.8 \%$ and grade 4 (severe cutaneous adverse reactions) in $0.7 \%$ of the cases in patients receiving TVR treatment. ${ }^{26}$ This study revealed that a baseline albumin level below $35 \mathrm{~g} / \mathrm{L}$ or platelet count below $100,000 / \mathrm{mm}^{3}$ or their combination are predictive factors of severe complications with triple therapy. ${ }^{26}$

\section{Impact of HCV on HRQOL}

Health is not only the absence of disease: it has been defined by the World Health Organization (WHO) as a concept integrating the notion of well-being in all domains of life (physical, mental, emotional, social, and spiritual). ${ }^{27}$

HRQOL refers to a patient's subjective assessment and includes a range of conditions that can affect the patient's perception of their state of health. ${ }^{28}$ The perception of HRQOL varies between individuals and is dynamic. HRQOL is not necessarily difficult to measure, but it does rely on patient self-report and is a subjective experience..$^{28}$ Usually, HRQOL data are obtained directly from the patient through an auto-questionnaire. Less frequently, the questionnaire is completed with the help of a care provider. ${ }^{28,29}$ The perception of HRQOL by the patient is not based on medical criteria such as laboratory values or evaluation of the degree of inflammation and fibrosis of the liver. Therefore, HRQOL is not always correlated with the severity of hepatitis C. Individuals who present the same clinical picture may have different expectations and report different quality of life. ${ }^{28}$

\section{Methods for the assessment of $\mathrm{HRQOL}$ in $\mathrm{HCV}$ patients}

Because of the complexity in determining HRQOL, various methods have been developed to assess the data. Different instruments and questionnaires, classified as generic or specific, have been proposed. ${ }^{28}$ Generic instruments are widely used and allow comparisons of different diseases and populations, ${ }^{28}$ however, generic instruments exhibit a number of limitations, of which the most important is that they do not allow specific aspects of a disease to be studied. ${ }^{28}$ For this reason, specific methods for assessing HRQOL are increasingly being developed. ${ }^{28}$ Currently, there are a number of specific questionnaires available regarding liver diseases in particular, hepatitis C. ${ }^{28,29}$

\section{Generic instruments}

The Medical Outcomes Study Short-Form 36 (SF-36) ${ }^{30}$ is an auto-questionnaire that calculates a profile of HRQOL. It comprises 36 questions that evaluate eight subgroups of health: physical activity; life and its relationship with others; physical pain; health perception; vitality; limitations due to psychological state; limitations due to physical state; psychological health; and health evolution. A new SF-36 version, specifically adapted to diseases such as hepatitis $\mathrm{C}$, has been proposed, ${ }^{31}$ as it has a detailed questionnaire including 69 parameters and a specific scale for $\mathrm{HCV}^{29}$

The Nottingham Health Profile is a general autoquestionnaire. ${ }^{28}$

The Sickness Impact Profile is a questionnaire, comprising 136 parameters, that is used infrequently. ${ }^{32}$

Fatigue state has been specifically evaluated by autoquestionnaires, that evaluates the impact of fatigue on physical, cognitive, and psychological domains, as well as by a visual analog scale. ${ }^{33}$

Social Functioning Questionnaire is a questionnaire that allows evaluation of professional activity. ${ }^{34}$

Health Utilities Index Mark 2 and Mark 3. 34,35

\section{Specific instruments}

Specific instruments adapted to chronic liver disease and hepatitis C include: the Chronic Liver Disease Questionnaire $;^{36}$ the Liver Disease Quality Of Life questionnaire; ${ }^{37}$ the Hepatitis Quality of Life Questionnaire; ${ }^{38}$ and The Nottingham Health Profile, supplemented and validated by another questionnaire specific for hepatitis $\mathrm{C}$, the Indicateur Spécifique de Montpellier. ${ }^{39}$

\section{HRQOL modifications relating to the period of assessment $\mathrm{HRQOL}$ in patients with chronic $\mathrm{HCV}$ infection out of treatment}

Several studies have revealed changes in HRQOL in patients with chronic HCV infection out of treatment compared to that of the control group. ${ }^{30,32,40-42}$ The notion of HCV contamination may alter the HRQOL of the patient because of the anxiety generated by the idea of contamination, its consequences on daily life, and its associated health risks. ${ }^{28,40}$ Fatigue is a very frequent symptom. ${ }^{33,41}$ Among patients with chronic hepatitis, those with HCV exhibited a significant alteration in SF-36 scores compared to patients infected by hepatitis $\mathrm{B}$ virus, with particularly low scores for mental function. ${ }^{41}$ Age and sex do not seem to play a role in HRQOL changes. ${ }^{29}$ HCV genotype and viral load are not associated with the level of fatigue responsible for the decrease in HRQOL. ${ }^{42,43}$ The severity of the histological lesions and transaminase elevation are also not correlated with changes in HRQOL. ${ }^{29}$ However, extrahepatic manifestations related to $\mathrm{HCV}-$ in particular 
arthralgia, paresthesia, myalgia, fibromyalgia, pruritus, and dry syndrome - do alter the HRQOL. ${ }^{43}$

Comorbidities may also affect HRQOL. ${ }^{29}$ SF-36 scores are correlated with past history of psychiatric disease or existence of addiction and somatic problems. ${ }^{29}$ HRQOL changes might also be caused by an effect of HCV on the brain, ${ }^{44}$ as there are data that suggest the presence of HCV in the central nervous system. ${ }^{45}$ Alteration of cognitive function has been reported more frequently in patients with minor chronic hepatitis compared to controls in recovery. This alteration was correlated with functional abnormalities in the brain as observed by magnetic resonance. ${ }^{44}$ However, addictive behavior and decompensation of cirrhosis appear to play more important roles than functional abnormalities of the brain in cognitive alteration in subjects contaminated by $\mathrm{HCV}^{29,46,47}$

\section{HRQOL during treatment of HCV infection}

The HRQOL in patients treated by interferon alone or in association with RBV decreases during the treatment, with SF-36 scores markedly decreasing within the first weeks of treatment. ${ }^{21,28-30,34,48-51}$ The most affected domains are physical activity, vitality, social function, and impact on emotion in social life. ${ }^{34}$ The alteration is more significant in the physical domain when interferon is associated with RBV. Bitherapy has been associated with a $50 \%$ decrease in professional productivity and work capacity. ${ }^{34}$ In a European study with treatment by interferon alone, $25 \%$ of the patients stopped their professional activity for 2 months, within the first trimester of treatment. If treatment was continued, 15\% of the active patients stopped their professional activity for 2 additional months. ${ }^{21}$

Finally, it is interesting to note that HRQOL alteration may be very differently evaluated by the patient than by the physician..$^{31,41}$

\section{HRQOL in patients with eradication of HCV after treatment}

The first studies performed in patients with a sustained virological response after treatment by interferon alpha alone showed a high improvement in HRQOL after treatment of HCV infection. ${ }^{31,41,42}$ These results have been confirmed by a study associating interferon alpha and RBV with an improvement in practically all domains of the SF-36 in patients with a good virological response, but no amelioration in virological nonresponders. ${ }^{30}$ However, even in patients with good responses, the improvement in HRQOL was not complete. Indeed, in this study, $33 \%$ of patients described a limitation in their social activity ( $53 \%$ before treatment), $40 \%$ remained tired (66\% before treatment), and 20\% exhibited limited professional activity ( $43 \%$ before treatment $).{ }^{30}$ Similar results were observed in another study. ${ }^{52}$

HRQOL improvement in patients with a sustained virological response may be related to the psychological effect associated with therapeutic success. However, in another study, the improvement of HRQOL in subjects with a chemical response, but without information on the virological response, was significantly better if the virological response had actually occurred. ${ }^{42}$ In a study comprising 912 patients randomly treated with interferon alone or in association with RBV, these results were confirmed. ${ }^{34}$ Before treatment, significant changes were observed in five of the eight domains in the SF-36; patients with a sustained virological response exhibited normalization in four of these five scores, which was not observed in the nonresponders. ${ }^{34}$ Similar results were observed in 1,441 patients, with or without cirrhosis, included in three randomized studies comparing PEG-IFN alpha-2a and standard interferon alpha-2a: patients with a good virological response exhibited an improvement in their HRQOL and a decrease in fatigue. ${ }^{52}$ In patients with cirrhosis, the improvement was mainly noted for the physical component. The lowest improvement seen was in the mental component, which might be explained by the persisting risk of complications associated with the cirrhosis. ${ }^{52}$

These results confirm that HCV eradication is associated with HRQOL improvements in its different domains: emotional, physical, and mental. However, normalization is not fully observed. In particular, asthenia may persist in about one out of three cases. The outcome of psychiatric side effects related to interferon discontinuation has not yet been well documented.

\section{Measures to improve adherence to treatment of HCV infection and TE}

Compared to other chronic diseases, $\mathrm{HCV}$ infection and treatment exhibit some particularities that deserve to be stressed for a better understanding of adherence difficulties in treatment of $\mathrm{HCV}$ infection. ${ }^{1-9}$ The major points are the following:

1. The HCV could be eradicated, in contrast with other viruses such as hepatitis B and human immunodeficiency virus (HIV);

2. The eradication could be obtained with a relatively limited duration of antiviral treatment (24-48 weeks);

3. In chronic hepatitis $\mathrm{C}$, the treatment induces an immediate worsening in the patient condition, in contrast to the 
treatment of most other chronic diseases, associated with an improvement in the patient condition;

4. This worsening is mainly caused by the numerous side effects of the treatment;

5. Therapeutic failures are mainly related to a lack of adherence to the treatment, which mostly result from the adverse effects of the antiviral therapy; and

6. The first generation of triple therapy is associated with additional particularities: risk of developing resistance, treatment insufficiency or intolerance because the virus has mutated and now produces antiproteases, and potential risks of drug interactions with other medications.

A decrease in adherence to treatment of $\mathrm{HCV}$ infection (bi- or triple therapy) is not limited to hepatitis C. It occurs in most chronic diseases that require long-term treatment. ${ }^{53}$ The suboptimal adherence observed in clinical trials in selected patients ${ }^{10,54-59}$ is even more marked in clinical practice. ${ }^{56}$ In addition, recent studies suggest that suboptimal adherence may also be linked to the patient's impression that no one is listening to them. ${ }^{60,61}$

In order to improve adherence and patient counseling while taking into account these specific aspects of hepatitis $\mathrm{C}$, various programs for TE have been developed over the past 15 years. $^{11}$

\section{Definition and characteristics of TE Initial definition of TE}

In a WHO-Europe report in 1998, TE was defined as follows:

Therapeutic patient education should enable patients to acquire and maintain abilities that allow them to optimally manage their lives with their disease. It is therefore a continuous process, integrated in health care. It is patient-centered; it includes organized awareness, information, self-care learning and psychosocial support regarding the disease, prescribed treatment, care, hospital and other health care settings, organizational information, and behaviour related to health and illness. It is designed to help patients and their families understand the disease and the treatment, cooperate with health care providers, live healthily, and maintain or improve their quality of life. ${ }^{62}$

Initial programs were based on those developed for other chronic diseases - in particular, HIV, diabetes, cardiovascular diseases, and rheumatic diseases. ${ }^{63-67}$ The initial objective of $\mathrm{TE}$ in hepatitis $\mathrm{C}$ was focused on observance of the antiviral treatment and primarily managed by the intervention of nurses..$^{15,68-72}$

\section{Modern concepts and characteristics of TE}

TE should be clearly defined and separated from education for health, although its purpose is similar: to improve the ability to maintain and develop health. However, the teaching practices are not similar. In TE, pedagogic choices should promote competence in maintaining healthy practices, as well as a respect for this healthy state. This double process is the major difficulty in the educative relationship. Living with a chronic disease requires that the patient obtains knowledge of the disease and its treatment and skills of auto-observation, auto-follow-up, autosupervision, and auto-adaptation of the treatment according to the various circumstances of their life. Consequently, the subject is confronted with the necessity of having an active and permanent role in their recovery process. This modification in the patient status necessitates that the health care providers (physician, nurse, etc) change their behavior, which is frequently instructive and paternalistic, in the search of a true partnership. This new dimension to the relationship does not change the medical responsibility and always relies on a pact of confidence, with the aim of permanently clarifying the intention and role of each partner. Consequently, education and care of patients with a chronic disease are complementary activities. The notion is that health should be considered as a complex good, leading patients to behave as the health producer, making their own therapeutic choices..$^{73-75}$

Finally, TE should be understood as the acquisition of decisional, technical, and social competency, with the purpose of making the patient able to make health choices, realize their own life plans, and use health care resources in the best manner. The patient should become able to recognize and interpret signs of health complications, for example, symptoms of anemia, early signs of depression, nutrition issues, and any skin reactions. ${ }^{73-75}$

Beyond these general concepts, TE should be adapted, not only to hepatitis $\mathrm{C}$, but also to the cultural patterns of the patient and their country, their religion, and the rules in the society in which they live. ${ }^{73-75}$

\section{Specific organization of TE in hepatitis C}

The patient is placed in the center of an organization, comprising various care workers who include social service professionals and medical staff. ${ }^{72}$ For hepatitis C, TE may be separated into three phases. 


\section{First phase: educative diagnosis}

This period starts just after the discovery and announcement of HCV infection to the patient. The TE team may make the first evaluation of the patient, with parameters shown in Figure 1 and Table 1, and perform the educative diagnosis (for example, providing knowledge to the patient of the disease and treatment; evaluation of their professional and social environment; and evaluation of the hepatic and extrahepatic consequences of HCV infection, comorbidities, potential addictions, and their will with regards to the TE team). ${ }^{73-75}$

Various tools have been developed to collect this type of information, comprising specific auto-questionnaires and questionnaire-guided interviews built by health professionals, patients themselves, and an association of patients who are part of the TE team. Obviously, these tools must be adapted to the specific cultural characteristics of the patient. ${ }^{73-75}$

Next, a synthesis of the patient situation may be done by the TE team to define their needs and design proposals for subsequent care. The conclusions and proposals are extremely variable, ranging between two extremes. The first is that HCV infection has no significant impact on the health and social life of the patient nor on their HRQOL; the patient may express no request of care or assistance, deny treatment, and just want to know how to organize the followup. At the other extreme is a patient with an unquestionable need for HCV treatment but in an extremely difficult situation to undergo treatment and with many other priorities. This patient may be homeless and/or have no job; no social security; severe addictions; comorbidities; and no will to start a difficult-to-realize treatment. The priority will be to evaluate how to improve these difficulties before engaging the patient in treatment.

If an antiviral treatment is indicated, the needs for achievement of the best condition should be evaluated at this stage to define the role of each health care member and prepare the patient and their personal environment (parents of the patient). The baseline HRQOL level must be assessed for further comparisons. When the appropriate conditions are obtained for treatment, the parameters of the second step should be considered. ${ }^{73-75}$

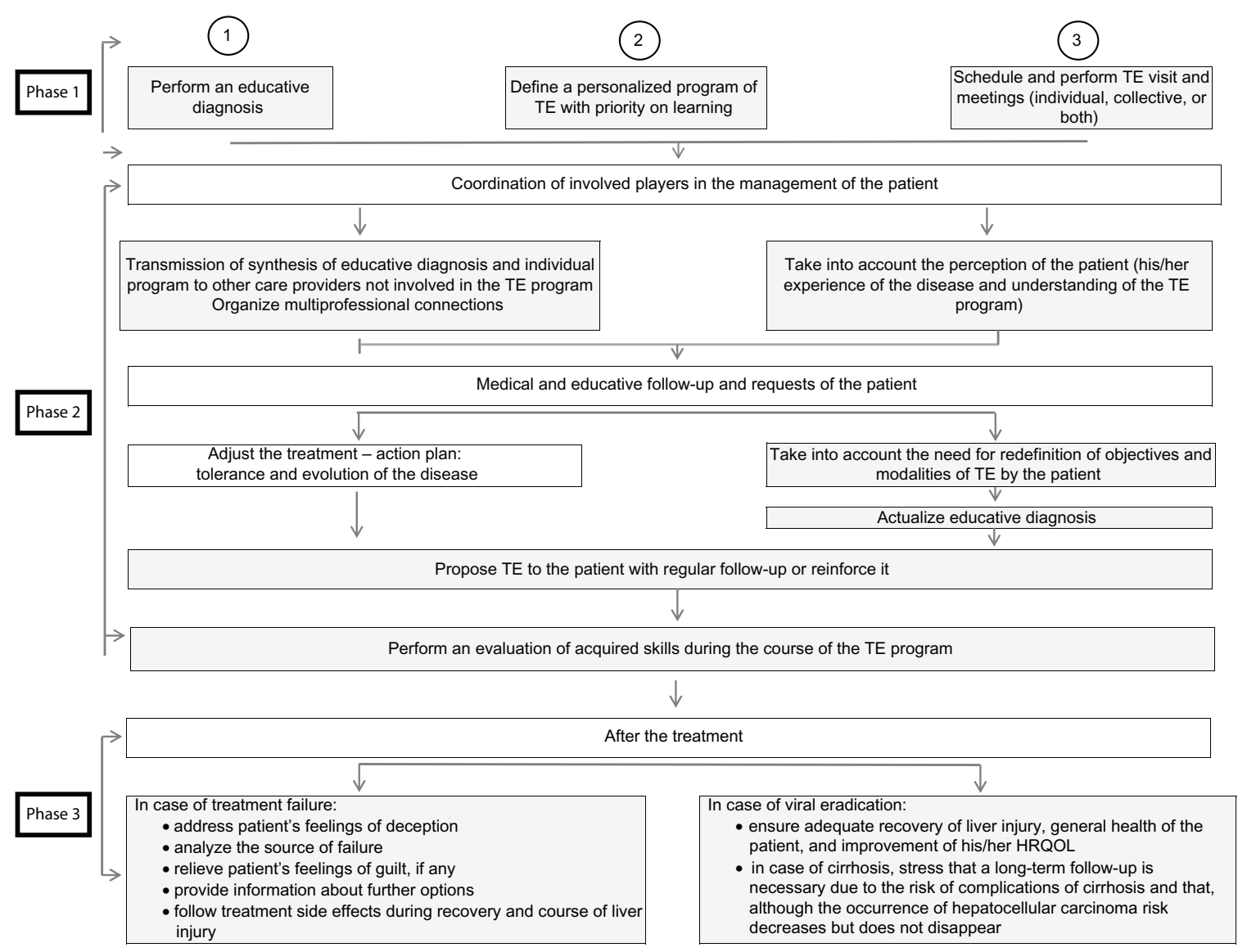

Figure I Organization of TE.

Abbreviations: HRQOL, health-related quality of life; TE, therapeutic education. 


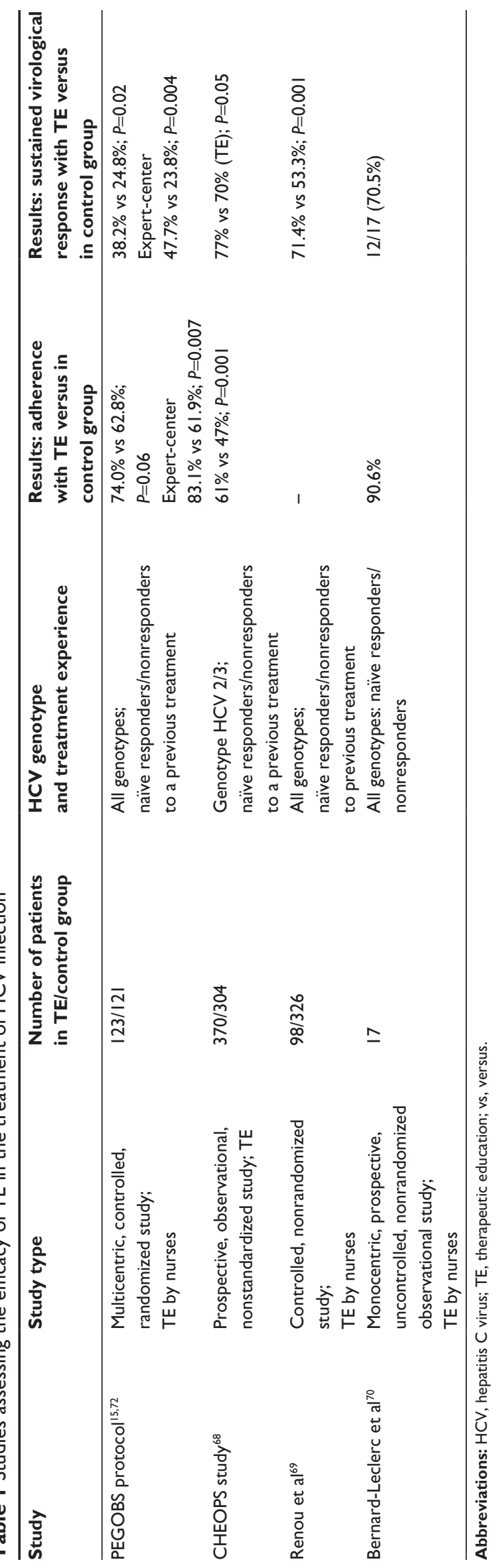

\section{Second phase: support during treatment}

The patient should have received the appropriate education to perform the treatment while in good condition (learning to inject PEG-IFN via a subcutaneous route and to take tablets of RBV and antiproteases on the appropriate schedule; learning about the probable or possible side effects of each component of the treatment and how to improve them by themselves)..$^{72-75}$

The calendar for visits, biological and virological controls requiring blood samples, and any other necessary examinations (ultrasound examination in cirrhotic patients) should be clearly indicated, by, for example, using a therapeutic booklet. This booklet should contain the relevant contact information (ie, phone numbers and email addresses) of the TE partners. Documents regarding HCV infection (ie, its potential consequences and treatment) that are specifically designed for the patients are also very useful.

The coordinator of the TE should evaluate how well the treatment is taking place with respect to medical appointments; biological and virological controls requiring blood samples; adherence to treatment; virological and biochemical responses to treatment; side effects; perceptions; modifications in the HRQOL of the patient and their family; social consequences; and any requirement for new educative actions or specific measures. The health providers usually have tools, such as specific questionnaires, to aid in this information collection.

The evaluations are performed step-by-step up to the end of the treatment, allowing for potential modifications to the treatment: modification of the antiviral dosage, sometimes premature discontinuation, and prescription of treatments (eg, pain killers, antidepressants, erythropoietin, alimentary supplements, treatments for skin reactions) for side effects.

\section{Third phase: support after treatment}

There are two situations that vary according to the response to the treatment. ${ }^{72-75}$

\section{Treatment failure}

The patient is very vulnerable in this situation, usually with a feeling of deception and absence of reward, despite their efforts to deal with difficulties and side effects. The confidence in the team may be decreased and the patient may be discouraged, thinking that they will never get rid of the virus and that the treatment might have been a bad decision.

In this circumstance, one may stress that many new treatments (with more than 20 molecules, including new antiproteases, anti-NS5A, and polymerase inhibitors) are under 
development, with evidence of high efficacy (90\%-100\%), few side effects with shorter duration, ${ }^{76-79}$ easy to take, in particular with oral treatments without interferon or RBV. ${ }^{76-79}$ The first marketing authorizations have been obtained for Sofosbuvir. ${ }^{77-79}$

\section{Virological recovery}

At this stage, there may be a discrepancy between the perception of the patient and that of the health team. From a medical point of view, the perspective may appear very positive: the viral infection has definitely disappeared, liver tests have normalized, and the long-term risks have disappeared. However, for the patient, the perception may be very different. In fact, the disappearance of the virus does not mean recovery from the disease. There are scant data illustrating long-term evaluation of patients after viral recovery. A recent prospective study suggested that patients with a sustained virological response more frequently exhibit obesity and cardiovascular risks. ${ }^{80}$ This risk is correlated with the number of previous treatments. $^{80}$

One should verify the health of the patient in all of the HRQOL domains: disappearance of liver disease and side effects of the treatment, restoration of social life, and improvement in their HRQOL.

In patients with cirrhosis, it is very important to underline that, although the risk of complications (hepatocellular carcinoma, bleeding from esophageal and gastric varices, portal vein thrombosis, etc) may have decreased with the viral suppression and the disappearance of liver inflammation, may have not altogether disappeared. ${ }^{8}$ Thus, a regular follow-up remains necessary. ${ }^{8}$

\section{Instruments and methods for TE}

Numerous instruments and methods have been developed. ${ }^{74,75}$

\section{Meetings}

Meetings with the patient are necessary in order to listen to the patient and assess their personal evolution with regard to their disease and treatment. Listening is fundamental and is a long and complex process that requires specific training.

\section{Individual meetings}

In general, initial meetings are done on an individual basis, with the care provided according to the educative diagnosis and, later, according to the situation of the patient with other members of the TE program. The presence of family members is desirable because they will be strongly involved in the disease and its treatment.

\section{Collective meetings and workshops}

It may be useful and encouraging for the patient to participate in collective meetings driven by specific topics.

\section{Instruments}

There are numerous guiding questionnaires, brochures, relevant cartoons, pictures, informational movies (on the disease, its treatment, and its prevention), testimonies by care providers or patients, and internet websites that can steer the patient to validated medical information and adequate social networks that may help them during their treatment.

\section{Choice of method and instruments}

One should avoid locking the patient into a particular course and instead take into account the advantages of each approach for their specific needs.

\section{Published experiences with TE in the management of hepatitis $C$}

There are a few published studies that assess the efficacy of TE in treatment of HCV infection which is mostly managed through the intervention of a nurse..$^{15,69-72}$ The organization, experimental design, and results of these studies are summarized in Table 1. These studies demonstrate that TE is associated with an improvement in adherence to the treatment and a higher virological response..$^{15,69-72}$ In PEGOBS, a single prospective, randomized, and multicenter study with a welldefined methodology, the beneficial effects were particularly observed in the most difficult-to-treat patients, who required 48 weeks of bitherapy, ${ }^{15}$ and are correlated with the experience of the nurse in question. ${ }^{72}$ Also, the PEGOBS study revealed that systematic TE in such conditions is associated with changes in the HRQOL in the emotional domain. ${ }^{73}$ Albeit positive, these experiences revealed that TE should not be limited to nurse intervention, but also rely on a more diversified team during treatment, comprising social care providers, pharmacists, physiotherapists, nutritionists, and specialists in addictology, as well as general practitioners, the patients themselves, and their families. ${ }^{15}$

\section{Conclusion and perspectives}

Chronic hepatitis $\mathrm{C}$ is unique among chronic diseases, because one may completely recover with a short-term treatment. The currently available treatments are associated 
with high efficacy, but are complex and associated with important side effects that are key points for the adherence and success of the treatment. Thus, the treatment triggers an alteration in the quality of life. Therefore, support by $\mathrm{TE}$ is essential at the different phases of hepatitis $C$ therapy: that is, before, during, and after treatment.

Many new treatments, with evidence of high efficacy, few side effects, and shorter duration, are upcoming. Indeed, the first marketing authorization has been obtained with sofosbuvir and will be obtained for other drugs in $2014 .{ }^{77-79}$ These new treatments, which are easier to maintain, will certainly change the landscape of adherence and the management of TE for HCV patients.

\section{Disclosure}

The authors report no conflicts of interest in this work.

\section{References}

1. Manns MP, McHutchison JG, Gordon SC, et al. Peginterferon alfa-2b plus ribavirin compared with interferon alfa- $2 \mathrm{~b}$ plus ribavirin for initial treatment of chronic hepatitis C: a randomised trial. Lancet. 2001;358: 958-965.

2. Fried MW, Shiffman ML, Reddy KR, et al. Peginterferon alfa-2a plus ribavirin for chronic hepatitis $\mathrm{C}$ virus infection. $N$ Engl J Med. 2002;347:975-982.

3. Ghany MG, Strader DB, Thomas DL, Seef LB. American Association for the Study of Liver Diseases. Diagnosis, management, and treatment of hepatitis C: an update. Hepatology. 2009;49:1335-1374.

4. Poordad F, McCone J Jr, Bacon BR, et al; SPRINT-2 Investigators. Boceprevir for untreated chronic HCV genotype 1 infection. $N$ Engl J Med. 2011;364:1195-1206.

5. Jacobson IM, McHutchison JG, Dusheiko G, et al; ADVANCE Study Team. Telaprevir for previously untreated chronic hepatitis $\mathrm{C}$ virus infection. N Engl J Med. 2011;364:2405-2416.

6. Bacon BR, Gordon SC, Lawitz E, et al; HCV RESPOND-2 Investigators. Boceprevir for previously treated chronic HCV genotype 1 infection. N Engl J Med. 2011;364:1207-1217.

7. Zeuzem S, Andreone P, Pol S, et al; REALIZE Study Team. Telaprevir for retreatment of HCV infection. $N$ Engl J Med. 2011; 364:2417-2428.

8. European Association for the Study of the Liver. EASL Clinical Practice Guidelines: management of hepatitis C virus infection. J Hepatol. 2011;55:245-264.

9. Russo MW, Fried MW. Side effects of therapy for chronic hepatitis C. Gastroenterology. 2003;124:1711-1719.

10. McHutchison JG, Manns M, Patel K, et al; International Hepatitis Interventional Therapy Group. Adherence to combination therapy enhances sustained response in Genotype-1 infected patients with chronic hepatitis C. Gastroenterology. 2002;123:1061-1069.

11. Larrey D. [Chronic hepatitis C: apart from antiviral treatment what other measures should be recommended?]. Gastroenterol Clin Biol. 2002;26 Spec No 2:B283-B290. French.

12. Weiss JJ, Bräu N, Stivala A, Swan T, Fishbein D. Review article: adherence to medication for chronic hepatitis $\mathrm{C}$ - building on the model of human immunodeficiency virus antiretroviral adherence research. Aliment Pharmacol Ther. 2009;30:14-27.

13. Evon DM, Esserman DA, Bonner JE, Rao T, Fried MW, Golin CE. Adherence to PEG/ribavirin treatment for chronic hepatitis $\mathrm{C}$ : prevalence, patterns, and predictors of missed doses and nonpersistence. J Viral Hepat. 2013;20:536-549.
14. Weiss JJ, Alcorn MC, Rabkin JG, Dieterich DT. The critical role of medication adherence in the success of boceprevir and telaprevir in clinical practice. J Hepatol. 2012;56:503-504.

15. Larrey D, Salse A, Ribard D, et al. Hepatitis C Network of Languedoc Roussillon (France). Education by a nurse increases response of patients with chronic hepatitis $\mathrm{C}$ to therapy with peginterferon- $\alpha 2 \mathrm{a}$ and ribavirin. Clin Gastroenterol Hepatol. 2011;9:781-785.

16. Zanini B, Benini F, Pigozzi MG, et al.Addicts with chronic hepatitis C: difficult to reach, manage or treat? World J Gastroenterol. 2013;19:8011-8019.

17. Zeremski M, Zibbell JE, Martinez AD, Kritz S, Smith BD, Talal AH. Hepatitis $\mathrm{C}$ virus control among persons who infect drugs requires overcoming barriers to care. World J Gastroenterol. 2013;19:7846-7851.

18. Russell M, Pauly MP, Moore CD, et al. The impact of lifetime drug use on hepatitis $\mathrm{C}$ treatment outcomes in insured members of an integrated health care plan. Drug Alcohol Depend. 2014;134:222-227.

19. Ramesh S, Sanyal AJ. Hepatitis C and nonalcoholic fatty liver disease. Semin Liver Dis. 2004;24:399-413.

20. Burger D, Back D, Buggisch P, et al. Clinical management of drugdrug interactions in HCV therapy: challenges and solutions. J Hepatol. 2013;58:792-800.

21. Roudot-Thoraval F, Abergel A, Allaert F, et al. Groupe d'Etude Pour Hépavir. [Hepavir, the first observational study of one cohort of patients treated with alpha-2a interferon, monotherapy. Evaluation of asthenia and its social consequences]. Gastroenterol Clin Biol. 2001;25: 1061-1066. French.

22. Larrey D, Couzigou P, Denis J. [Chronic hepatitis C: management of side effects of treatment]. Gastroenterol Clin Biol. 2007;31: 4S20-4S28. French.

23. Horsmans Y. Chronic hepatitis C, depression and interferon. J Hepatol. 2005;42:788-789.

24. Castera L, Constant A, Henry C, et al. Impact on adherence and sustained virological response of psychiatric side effects during peginterferon and ribavirin therapy for chronic hepatitis C. Aliment Pharmacol Ther. 2006;24:1223-1230.

25. Raison CL, Borisov AS, Broadwell SD, et al. Depression during pegylated interferon-alpha plus ribavirin therapy: prevalence and prediction. J Clin Psychiatry. 2005;66:41-48.

26. Hézode C, Fontaine H, Dorival C, et al; CUPIC Study Group. Triple therapy in treatment-experienced patients with HCV-cirrhosis in a multicentre cohort of the French Early Access Programme (ANRS CO20 CUPIC)-NCT01514890. J Hepatol. 2013;59:434-441.

27. Constitution of the World Health Organization. In: Chronicle of the World Health Organization. Vol 1. Geneva: World Health Organization; 1947.

28. Strauss E, Dias Teixeira MC. Quality of life in hepatitis C. Liver Int. 2006;26:755-765.

29. Spiegel BM, Younossi ZM, Hays RD, Revicki D, Robbins S, Kanwal F. Impact of Hepatitis $\mathrm{C}$ on health related quality of life: a systematic review and quantitative assessment. Hepatology. 2005;41:790-800.

30. Ware JE Jr, Bayliss MS, Mannocchia M, Davis GL. Health-related quality of life in chronic hepatitis $\mathrm{C}$ : impact of disease and treatment response. The Interventional Therapy Group. Hepatology. 1999;30: 550-555.

31. Leplège A, Mesbah M, Marquis P. [Preliminary analysis of the psychometric properties of the French version of an international questionnaire measuring the quality of life: the MOS SF-36 (version 1.1)]. Rev Epidemiol Sante Publique. 1995;43:371-379. French.

32. Davies GL, Balart LA, Schiff ER, et al. Assessing health-related quality of life in chronic hepatitis C using the Sickness Impact Profile. Clin Ther. 1994;16:334-343.

33. Sarkar S, Jiang Z, Evon DM, Wahed AS, Hoofnagle JH. Fatigue before, during and after antiviral therapy of chronic hepatitis $\mathrm{C}$ : results from the Virahep-C study. J Hepatol. 2012;57:946-952.

34. McHutchison JG, Ware JE Jr, Bayliss MS, et al; Hepatitis Interventional Therapy Group. The effects of interferon alpha-2b in combination with ribavirin on health related quality of life and work productivity. J Hepatol. 2001;34:140-147. 
35. Torrance GW, Feeny DH, Furlong WJ, Barr RD, Zhang Y, Wang Q. Multi-attribute utility function for a comprehensive health status classification system. Health Utilities Index Mark 2. Med Care. 1996;34: 702-722.

36. Younossi ZM, Guyatt G, Kiwi M, Boparai N, King D. Development of disease specific questionnaire to measure heath related quality of life in patients with chronic liver disease. Gut. 1999;45:295-300.

37. Gralnek IM, Hays RD, Kilbourne A, et al. Development and evaluation of the Liver Disease Quality of Life instrument in persons with advanced, chronic liver disease - the LDQOL 1.0. Am J Gastroenterol. 2000;95:3552-3565.

38. Bayliss MS, Gandek B, Bungay KM, Sugano D, Hsu MA, Ware JE Jr. A questionnaire to assess the generic and disease-specific health outcomes of patients with chronic hepatitis C. Qual Life Res. 1998;7:39-55.

39. Remy AJ, Daurès JP, Tanguy G, et al. [Measurement of the quality of life in chronic hepatitis $\mathrm{C}$ : validation of a general index and specific index. First French results]. Gastroenterol Clin Biol. 1999;23:1296-1309. French.

40. Rodger AJ, Jolley D, Thompson SC, Lanigan A, Crofts N. The impact of diagnosis of hepatitis C virus on quality of life. Hepatology. 1999;30:1299-1301.

41. Foster GR. Hepatitis C virus infection: quality of life and side effects of treatment. J Hepatol. 1999;31 Suppl 1:250-254.

42. Bonkovsky HL, Woolley JM. Reduction of health-related quality of life in chronic hepatitis $\mathrm{C}$ and improvement with interferon therapy. The Consensus Interferon Study Group. Hepatology. 1999;29:264-270.

43. Cacoub P, Poynard T, Ghillani P, et al. Extrahepatic manifestations of chronic hepatitis C. MULTIVIRC Group. Multidepartment Virus C. Arthritis Rheum. 1999;42:2204-2212.

44. Forton DM, Thomas HC, Murphy CA, et al. Hepatitis C cognitive impairment in a cohort of patients with mild liver disease. Hepatology. 2002;35:433-439.

45. Laskus T, Radkowski M, Bednarska A, et al. Detection and analysis of hepatitis C virus sequences in cerebrospinal fluid. J Virol. 2002;76: 10064-10068.

46. Häuser W, Zimmer C, Schiedermaier P, Grandt D. Biopsychosocial predictors of health-related quality of life in patients with chronic hepatitis C. Psychosom Med. 2004;66:954-958.

47. Córdoba J, Flavià M, Jacas C, et al. Quality of life and cognitive function in hepatitis $\mathrm{C}$ at different stages of liver disease. J Hepatol. 2003;39:231-238.

48. Obhrai J, Hall Y, Anand BS. Assessment of fatigue and psychologic disturbances in patients with hepatitis $\mathrm{C}$ virus infection. $J$ Clin Gastroenterol. 2001;32:413-417.

49. Piche T, Tran A. [Fatigue in patients with chronic hepatitis C: a sign to look for]. Gastroenterol Clin Biol. 2001;25:1059-1060. French.

50. Hassanein T, Cooksley G, Sulkowski M, et al. The impact of peginterferon alfa-2a plus ribavirin combination therapy on health-related quality of life in chronic hepatitis C. J Hepatol. 2004;40:675-681.

51. Poynard T, Cacoub P, Ratziu V, et al; Multivirc group. Fatigue in patients with chronic hepatitis C. JViral Hepat. 2002;9:295-303.

52. Berstein B, Kleinman J, Barker CM, Revicki DA, Green J. Relationship of health-related quality of life to treatment adherence and sustained response in chronic hepatitis C patients. Hepatology. 2002;35: 704-708.

53. Osterberg L, Blaschke T. Adherence to medication. $N$ Engl $J$ Med. 2005;353:487-497.

54. Waeber B, Leonetti G, Kolloch R, McInnes GT. Compliance with aspirin or placebo in the Hypertension Optimal Treatment (HOT) study. $J$ Hypertens. 1999;17:1041-1045.

55. Claxton AJ, Cramer J, Pierce C. A systematic review of the associations between dose regimens and medication compliance. Clin Ther. 2001;23:1296-1310.

56. Cramer J, Rosenheck R, Kirk G, Krol W, Krystal J; VA Naltrexone Study Group 425. Medication compliance feedback and monitoring in a clinical trial: predictors and outcomes. Value Health. 2003;6:566-573.
57. Dunbar-Jacob J, Mortimer-Stephens MK. Treatment adherence in chronic disease. J Clin Epidemiol. 2001;54 Suppl 1:S57-S60.

58. Haynes RB, McKibbon KA, Kanani R. Systematic review of randomised trials of interventions to assist patients to follow prescriptions for medications. Lancet. 1996;348:383-386.

59. Miller NH. Compliance with treatment regimens in chronic asymptomatic diseases. Am J Med. 1997;102:43-49.

60. Balfour L, Cooper C, Tasca GA, Kane M, Kowal J, Garber G. Evaluation of health care needs and patient satisfaction among hepatitis $\mathrm{C}$ patients treated at a hospital-based, viral hepatitis clinic. Can J Public Health. 2004;95:272-277.

61. Zickmund S, Hillis SL, Barnett MJ, Ippolito L, LaBrecque DR. Hepatitis $\mathrm{C}$ virus-infected patients report communication problems with physicians. Hepatology. 2004;39:999-1007.

62. Organisation Mondiale de la Santé. Education Thérapeutique du Patient [Therapeutic Patient Education]. Geneva: World Health Organization; 1998. Available from: http://www.euro.who.int/_data/ assets/pdf_file/0009/145296/E93849.pdf. Accessed March 1, 2014. French.

63. Massip P, Cuzin L, Delpierre C, Garbay MF, Rousselle-Koch. oRchestra: une expérience pour améliorer la prise en charge globale des patients infectés par le VIH [oRchestra: an experience in order to improve the global care of HIV infected patients]. Med Mal Infect. 2003;33:117-121. French.

64. Pradier C, Bentz L, Spire B, et al. Efficacy of an educational and counseling intervention on adherence to highly active antiretroviral therapy: French prospective controlled study. HIV Clin Trials. 2003;4:121-131.

65. Tuldrà $\mathrm{A}, \mathrm{Wu} \mathrm{AW}$. Interventions to improve adherence to antiretroviral therapy. J Acquir Immune Defic Syndr. 2002;31 Suppl 3:S154-S157.

66. Haynes RB, McDonald H, Garg AX, Montague P. Intervention for helping patients to follow prescriptions for medications. Cochrane Database Syst Rev. 2002;2:CD000011.

67. Donnan PT, MacDonald TM, Morris AD. Adherence to prescribed oral hypoglycaemic medication in a population of patients with Type 2 diabetes: a retrospective cohort study. Diabet Med. 2002;19:279-284.

68. Cacoub P, Ouzan D, Melin P, et al. Patient education improves adherence to peg-interferon and ribavirin in chronic genotype 2 or 3 hepatitis $\mathrm{C}$ virus infection: a prospective, real-life, observational study. World J Gastroenterol. 2008;14:6195-6203.

69. Renou C, Lahmek P, Pariente A, et al. Impact of therapeutic education on the outcome of chronic hepatitis C treatment. Hepatology. 2009;729A (abstract)

70. Bernard-Leclerc J, Conort O, Bacq Y, Antier D. Impact d'un programme d'éducation thérapeutique sur les connaissances, l'observance et la satisfaction des patients traités pour hépatite chronique virale $\mathrm{C}$ [Impact of a therapeutic education program on the knowledge, the adherence and the satisfaction of the patients treated for viral chronic hepatitis C]. Ther Patient Educ. 2011;3:21-33.

71. Larrey D, Salsé A, Castelli C, et al. Groupe PEGOBS. Education thérapeutique systématique par une infirmière chez les patients atteints d'hépatite chronique $C$, traités par Interféron-Pégylé alpha2a - ribavirine (Protocole PEGOBS): impact sur la qualité de vie [Systematic therapeutic education by a nurse in patients with chronic hepatitis $C$, treated with pegylated interferon-alpha2a - ribavirin (PEGOBS Protocol): impact on quality of life]. Gastroenterol Clin Biol. 2009;33:63 (abstract CA-12). French.

72. Larrey D. Un exemple d'éducation thérapeutique par un infirmière sur l'observance et l'efficacité du traitement par bithérapie peginterferon-alpha2-ribavirine dans l'hépatite chronique C: protocole PEGOBS [An example of therapeutic education by a nurse on compliance and efficacy of treatment with bitherapy peginterferon-alpha2-ribavirin in chronic hepatitis C: PEGOBS protocol]. Bull Epidemiol Hebd. 2012;29-30:350-354. French. 
73. Surjadi M, Torruellas C, Ayala C, Yee HF Jr, Khalili M. Formal patient education improves patient knowledge of hepatitis $\mathrm{C}$ in vulnerable populations. Dig Dis Sci. 2011;56:213-219.

74. Simon D, Traynard PY, Bourdillon F, Gagnayre R, Grimaldi A. Education Thérapeutique. Prévention et Maladies Chroniques [Therapeutic Education. Prevention and Chronic Diseases]. 2nd ed. Issy les Moulineaux: Elsevier Masson; 2009. French.

75. Thompson MA, Mugavero MJ, Amico KR, et al. Guidelines for improving entry into and retention in care and antiretroviral adherence for persons with HIV: evidence-based recommendations from an International Association of Physicians in AIDS Care panel. An Intern Med. 2012;156:817-833.

76. Bourlière M, Khaloun A, Wartelle-Bladou C, et al. Chronic hepatitis C: treatments of the future. Clin Res Hepatol Gastroenterol. 2011 35 Suppl 2:S84-S95.
77. Osinusi A, Meissner EG, Lee YJ, et al. Sofosbuvir and ribavirin for hepatitis $\mathrm{C}$ genotype 1 in patients with unfavorable treatment characteristics: a randomized clinical trial. JAMA. 2013;310:804-811.

78. Lawitz E, Mangia A, Wyles D, et al. Sofosbuvir for previously untreated chronic hepatitis C infection. N Engl J Med. 2013;368:1878-1887.

79. Jacobson IM, Gordon SC, Kowdley KV, et al; POSITRON Study; FUSION Study. Sofosbuvir for hepatitis C genotype 2 or 3 in patients without treatment options. N Engl J Med. 2013;368:1867-1877.

80. Chambon-Augoyard C, Faure S, Pageaux GP, Daurès JP, Larrey DG. Is there a risk to develop obesity and metabolic syndrome in patients with chronic hepatitis $\mathrm{C}$ after treatment-induced long term virological eradication? Hepatology. 2011;54:1619:1127A.

\section{Publish your work in this journal}

Patient Preference and Adherence is an international, peer-reviewed, open access journal focusing on the growing importance of patient preference and adherence throughout the therapeutic continuum. Patient satisfaction, acceptability, quality of life, compliance, persistence and their role in developing new therapeutic modalities and compounds to optimize clinical outcomes for existing disease states are major areas of interest. This journal has been accepted for indexing on PubMed Central. The manuscript management system is completely online and includes a very quick and fair peer-review system. Visit http://www.dovepress.com/ testimonials.php to read real quotes from published authors.

Submit your manuscript here: http://www.dovepress.com/patient-preference-and-adherence-journal 